\title{
Scientometric Analysis
}

\section{of Human Microbiome Project}

\author{
Stella Pasternak ${ }^{\mathrm{a}}$ and Rem Khlebobpros ${ }^{\mathrm{b}, \mathrm{c*}}$ \\ ${ }^{a}$ New England Research Institute \\ Watertown, MA 02472, USA \\ ${ }^{b}$ Krasnoyarsk Scientific Centre SB RAS \\ Krasnoyarsk, 660036, Russia \\ ${ }^{c}$ Siberian Federal University \\ 79 Svobodny, Krasnoyarsk, 660041, Russia
}

Received 24.09.2016, received in revised form 24.03.2017, accepted 12.05.2017

The appearance, in 2008, of the Human Microbiome Project, which is comparable in importance to the Human Genome Project, is a direct evidence of awareness of microsymbionts importance for all aspects of human health. Quality scientometric analysis of research works carried out in this field and prospects of their development is the aim of this article.

Keywords: project, human microbiota, social important studies.

DOI: 10.17516/1997-1370-0116.

Research area: sociology.

\section{Introduction}

In 2008 the National Institute of Health (NIH) US launched the research comparable in importance and significance to the study of the Human Genome Project. This project comprehensively analyses human microbiota, which is populated by over 100 trillion microorganisms living in our gut, mouth, skin and other parts of the body.

These microbial communities have many useful functions related to the maintenance of life. The microorganisms are needed for digestion, protection from invading pathogenic bacteria, viruses and fungi. Moreover they are also involved in synthesizing the necessary nutrients and vitamins.
The total number of genes associated with human microbial ecosystem exceeds the total number of human genes by a factor of 100:1. That is why this study by its importance and significance is comparable with the study of the human genome project.

Traditionally, the microorganisms have been studied as cultures in laboratories. However, most types of human-associated microbial species have never been successfully grown in the laboratory. Apparently, their growth is dependent on the specific conditions or substances which have not been duplicated in the laboratory.

Advances in DNA sequencing technologies and the so-called "omics" technologies such as

(C) Siberian Federal University. All rights reserved

* Corresponding author E-mail address: stpasternak@yahoo.com; olikru@yandex.ru 
transcriptomics, proteomics and metabolomics have created new research opportunities, named metagenomics. They allow a comprehensive examination of microbial communities from the human body without the need for cultivation. They also allow to measure biological properties of microbial communities.

Instead of studying the genomes of individual bacterial strains, metagenomic approach allows us to analyze the genetic material collected directly from the microbial communities without the need for separate cultivation of microbes. In Human Microbiome Project, this approach in addition to the genetic analysis of available reference strains provides unprecedented information on the importance of the complexity of human microbial communities.

In general, it is planned to perform the detailed analysis and description of more than 1,000 different physiological conditions and deliver this information to be deposited in the public library. This information will serve as an invaluable resource for the scientific community.

Over the past 7 years, a lot of work has been conducted to study this issue and a lot of articles have been written.

We will focus only on a few (3) areas of this research.

\section{The Connection Between Intestinal Microflora Disorders and Mental Disorders}

Today no one doubts the ability of the intestinal microbiota to communicate with the brain and therefore to modulate behavior. Intestinal microbiota interacts with the body, forming the necessary connections that regulate homeostasis.

Therefore changes in the intestinal microflora affect both the normal physiology and the ability of the diseases occurrence and, in particular, mental diseases. Despite the uniqueness of the intestinal bacterial flora of each person, there's a certain balance, which corresponds to the state of "health". Thus, in many experiments, mice free of microbes demonstrated changes in the stress sensitivity and behavior, indicating decreased anxiety compared to normal mice. However, the mice infected with pathogenic bacteria, showed an increase of anxiety and a decreased activity.

Another large group of studies conducted in germ-free animals and in animals exposed to pathogenic bacterial infections, as well as in animals exposed to probiotics or antibiotic drugs demonstrates the importance of the intestinal microflora in the regulation of anxiety, mood, cognitive or pain.

This accumulation of data show that the intestinal microbiota is associated with the central nervous system - possibly through the nervous, endocrine and immune ways - and thereby affects brain function and behavior.

We have already mentioned that a wide variety of experiments were used to study the microflora influence on brain functions, they include the use of antibiotics, treatment with probiotics, studies of infections of the gastrointestinal tract, and studies of sterile animals.

Among the above mentioned experiments, there are tests on transplantation of fecal microbiota. Researchers, such as Mark Lai from Health Sciences Center at the Texas Technological University for several years engaged in transplantation of fecal microflora of newborn monkey in the gut of another newborn monkey, so that the recipient will end up with a completely new set of germs - and, if all goes as expected with the changed development of the nervous system.

In addition, microbes in our intestines secrete large amounts of chemicals. The researchers found that, among these chemicals there are many same substances that are used by our neurons for 
communication and mood regulation, such as dopamine, serotonin and gamma-aminobutyric acid (GABA).

Intestinal germs "communicate" with the nervous system, using the same chemicals that transmit messages to the brain.

Today, therefore, anxiety, depression and several childhood disorders, including autism and hyperactivity associated with gastrointestinal disorders.

These findings were also confirmed by many experiments, such as:

- To test how organisms respond to stress, Petri dishes were filled with bovine serum broth. Norepinephrine, neurochemical compound that mammals produce during stress, was added to some of them. On next day, the results were clear: control dishes contained almost no microbes, in contrast, the dishes with norepinephrine were filled with bacteria, they responded well to stress.

- To check whether the bacteria can cause stress, white mice were fed with liquid solution of Campylobacter jejuni, bacteria which can cause food poisoning in humans, but does not induce an immune response in mice. Bacteria-fed mice looked healthy as mice in the control group. But when the mice were passed through a plastic maze, raised on a few feet above the floor, the bacteria-fed mice were more passive, seemed more anxious than mice in the control group.

In 2011, a group of researchers from the Cork College in Ireland, and McMaster University in Ontario, published a study which became one of the most famous experiments, binding the bacteria in the gut with the brain responses.

Laboratory mice were dropped in the high cylindrical water towers, in what is known as the forced swim test, which measures how long (usually more than six minutes), the mice will swim before they realize that they can neither touch the bottom nor get out. The amount of time the mouse swims used, as a way to measure the so-called 'behavioral despair" (Antidepressants, such as Zoloft and Prozac, initially were tested by this forced swim test). During few weeks a small group of healthy rodents were fed with a mixture of broth with Lactobacillus rhamnosus, bacteria that are found in the human body, and are also used for the fermentation of milk into yogurt. It is known that this type of bacteria releases huge amounts of GABA amino acid, a major inhibitory neurotransmitter of the central nervous system. GABA inhibits the hyperactivity, calms, regulates the muscle tone which explains why the most common anti-anxiety drugs such as Valium and Xanax work by acting on GABA receptors. It was found that mice that were fed with the above mentioned mixture spent less time in the immobile state and float longer. They behaved as if they were taking Prozac and were more relaxed.

These results indicate that bacteria somehow alter the chemical reactions in the nervous system.

Based on the above tests and all the information received, the new concept of binding the bacteria in the gut with the brain functions, suggests that modulation of intestinal microflora may be a primary strategy in developing new therapeutic agents for central nervous system disorders.

\section{The Connection Between the Intestinal Microflora Disorders and Inflammatory Bowel Diseases}

Two major human inflammatory bowel diseases (IBD) Crohn's disease (CD) and ulcerative colitis (UC) are idiopathic recurrent disorders. They are characterized by the chronic inflammation of the mucosa of the gastrointestinal tract. In the US alone approximately 1.5 million people affected by them, and the incidence is increasing every year.

$\mathrm{CD}$ and $\mathrm{UC}$ are complex diseases, their severity and symptoms can manifest differently. 
Although it has become clear that inflammatory bowel diseases (IBD) are associated with the entire microbial ecosystem of the gut and gastrointestinal microbes affect the pathogenesis of these disorders, the types of microbes involved in the pathogenic processes were not adequately described.

Few mechanisms can explain the complex relationship between the commensal microbiota and IBD disorders: dysbiosis of conventional microbiota; functionally altered commensal bacteria; host genetic defects in containing commensal microbiota. These mechanisms have a common theme: all alter the host immune response to commensal bacteria.

Over the past few years a number of studies and experiments conducted by scientists such as Professor R. Balfour Sartor from North Carolina State University; Professor Henry Sokol from the Gastroenterology Department in the St. Anthony's Hospital in Paris have demonstrated that:

- in some cases, a change in the microbial composition leads to overstimulation of the immune system and /or enhanced mucosal permeability;

- in other patients, an increase in the number of bacteria and changes occurring with some microbes that normally inhabit the large intestine in particular with Escherichia coli, cause abnormal aggressive immune responses that lead to the injury of the intestinal wall.

Several studies analyzed the tissue samples from the gastro-intestinal tract obtained surgically from UC and CD patients with the samples received from healthy individuals. Comparative analysis showed statistically significant differences between the microbiota of patients and healthy people.

The results show that a subset of $\mathrm{CD}$ and UD samples contained abnormal microbiota characterized by the depletion of commensal bacteria, in particular members of the Firmicutes and Bacteroidetes groups.

Therefore the treatment of some forms of IBD can be conducted by the rehabilitation of the identified microbial imbalances and the use of properly selected probiotics. These methods appear the most promising in the treatment of IBD.

\section{The Connection Between \\ the Intestinal Microflora Disorders and the Diseases of the Immune System}

As I mentioned in this article the microbiota in human body, is populated by over 100 trillion microorganisms.

The greatest quantity of these microorganisms present in the distal parts of the intestinal tract and most of the intestinal bacteria are the gram-negative anaerobes. Microbes that inhabit the intestinal tract under certain adverse conditions are able to overcome the protective mechanisms and cause pathological reactions.

Imbalance in the composition of the bacterial flora, known as dysbacteriosis, which occurs as a result of the disorders of the immune system components, antibiotic treatment and an unbalanced diet, which is common in Western countries, is closely associated with allergies, asthma, inflammatory bowel disease, type 1 diabetes and a variety of other autoimmune diseases.

The intestinal microflora contains a number of components that can activate the innate and acquired immunity.

The mucosal immune system has developed a special, anti-inflammatory mechanisms to eliminate and /or reduce the effects of nonhazardous, food and air antigens and thus provides local defense mechanisms against environmental threats (for example, invasion of pathogens).

On the other hand, unlimited immune activation in response to signals sent from the 
bacteria, may pose a risk of inflammation and of serious disease. Therefore mucosal immune reactions require precise regulation by the immune system. This requirement is met by several mechanisms, such as:

- a highly developed innate mechanism that ensures the proper function of mucosal barrier;

- the presence of unique types of lymphocytes;

- polymeric immunoglobulins transport through the epithelial cells.

The important role of intestinal bacteria in the development of optimal functioning of the immune system was demonstrated in experiments with sterile animals and with animals susceptible to pathogens, chemical and /or biological effects.

Such studies were carried out by scientists like professor D.L. Round of the National Center for Biotechnology Information; Sarkiz Mazmanian of the California Institute of Technology. Professor Mazmanian created treatment for mice based on the intestinal microflora. Initially he created diseased mice by injecting pregnant individuals with doublestranded RNA, which is chemically similar to DNA, but performs other functions in the cell.

The immune system of the rodent perceived this RNA injection as the virus, and began to react with fever and cytokine levels increase, destroying the normal microflora.

Then, their state of health was normalized, by a strain of probiotic bacteria of the Bacteroides fragilis.

After such intervention mice gave birth to pups with unhealthy immune system and microflora. Then the mice's health was brought back to norm by using the probiotic strain of the Bacteroides fragilis.

On the basis of the above, investigations and observations, it has been suggested to use microflora and its components with strong immunostimulant properties (e.g. peptidoglycans, superantigens, bacterial DNA) in the treatment of a variety of complex, multifactorial diseases, including inflammatory bowel disease, periodontal disease, atherosclerosis, rheumatoid arthritis, and allergies.

\section{Conclusions}

Let's try to make some conclusions:

1. Human microbiota is populated by over 100 trillion microorganisms. Microbial communities perform numerous, necessary, vital functions related to the maintenance of life itself. The microbial community under adverse conditions can cause a wide variety of diseases. Designated correct effect on the microflora can cure various diseases. Not only the microbial genome is extremely diverse, but specific types of microbes are distinct for each person /animal. An intestinal bacterium emits large quantities of chemicals and is able to communicate with the brain. It modulates the behavior that regulates mood and can contribute to mental illness. The intestinal microflora contains a number of components that can activate the innate and acquired immunity.

2. The microbiota study uses several basic methods. As mentioned in this article, most types of human bacteria is not yet possible, to grow in the laboratory. Therefore, the microbial DNA is collected and analyzed. The genetic material of entire microbial communities is analyzed too. Scientists have measured the diversity of microbes. For this purpose, they use a so-called phylogenetic tree. Microbial community that covers a large part of the tree is considered to be more diverse. Scientists compare the human microbial communities in relation to each other. The microbial communities in healthy and sick people are compared. The relationships between microflora disorders and diseases that 
arise because of these specific disorders are now being studied. Experiments that demonstrate the changes caused by the introduction of specific microbes are conducted and analyzed.

3. Based on of the accumulated experience and knowledge, the following methods for the treatment of various complex diseases using microflora and /or its components, look promising: the creation of the new types of probiotics; the use of properly selected probiotics that can improve concrete, specific symptoms of diseases; transplantation of fecal microflora from the donor to the recipient; development of a new generation of drugs; the formation of new forms and types of diets.

At the end we want to discuss some extremely important factors not mentioned in this article.

- Microbes are constantly exchanging genetic material not only among themselves but also with other species, such as eukaryotes and viruses. Therefore, microbes and microbial communities are constantly evolving, acquire new properties. Therefore, in microbiota study and new drugs development, these constant changes should be considered.

- Based on the genetic characteristics of the gut bacteria, all people are divided into three enterotypes. Enterotype of each person manifests itself in different reactions to food, diet and medication. This implies that in spite of the intensive research and attempts to create new kinds and types of diets, today, yet, there are no universal recipes in this area.

- It is worth noting the almost complete lack of application of mathematical modeling methods in this research area. We should expect to see this kind of work, in particular on the population dynamics of the human microbial communities.

\section{Acknowlegments}

The authors thank Professors V.N. Danilenko and V.G. Soukhovolsky and Dr. I.R. Fomina for fruitful discussions.

\section{References}

Collins, S.M., Bercik P. (2009) The Relationship between Intestinal Microbiota and the Central Nervous System in Normal Gastrointestinal Function and Disease, In Gastroenterology, 136(6), 20032014. DOI: 10.1053/j.gastro.2009.01.075.

Cryan, J.F., Dinan, T.G. (2012) Mind-altering Microorganisms: the Impact of the Gut Microbiota on Brain and Behaviour, In Nat Rev Neurosci, 13(10), 701-712. DOI: 10.1038/nrn3346.

Cryan, J.F., O’Mahony, S.M. (2011) The Microbiome-gut-brain Axis: from Bowel to Behavior, In Neurogastroenterol Motil, 23(3), 187-192. DOI: 10.1111/j.1365-2982.2010.01664.x.

Mazmanian, S.K., Round, J.L., Kasper, D.L. (2008) A Microbial Symbiosis Factor Prevents Intestinal Inflammatory Disease, In Nature, 453(7195), 620-625. DOI: 10.1038/nature07008.

Frank, D.N., St Amand, A.L., Feldman, R.A., Boedeker, E.C., Harpaz, N., Pace, N.R. (2007) Molecular-phylogenetic Characterization of Microbial Community Imbalances in Human Inflammatory Bowel Diseases, In Proc Natl Acad Sci U S A, 104(34), 13780-13785.

Sartor, R.B. (2008) Microbial Influences in Inflammatory Bowel Diseases, In Gastroenterology, 134(2):577-594. DOI: 10.1053/j.gastro.2007.11.059.

Clemente, J.C., Ursell, L.K., Parfrey, L.W., Knight, R. (2012) The Impact of the Gut Microbiota on Human Health: an Integrative View, In Cell, 148(6), 1258-1270. DOI: 10.1016/j.cell.2012.01.035. 
Ott, S.J., Musfeldt, M., Wenderoth, D.F., Hampe, J., Brant, O. (2004) Reduction in Diversity of the Colonic Mucosa Associated Bacterial Microflora in Patients with Active Inflammatory Bowel Disease, In Gut, 53(5), 685-93.

Sokol, H., Pigneur, B., Watterlot, L. (2008) Faecalibacterium prausnitzii is an Anti-inflammatory Commensal Bacterium Identified by Gut Microbiota Analysis of Crohn Disease Patients, In Proc Natl Acad Sci U S A, 105(43), 16731-16736. DOI: 10.1073/pnas.0804812105.

Round, J.L., Mazmanian, S.K. (2009) The Gut Microbiota Shapes Intestinal Immune Responses During Health and Disease, In Nat Rev Immunol, 9(5), 313-323. DOI: 10.1038/nri2515.

Noverr, M.C., Huffnagle, G.B. (2004) Does the Microbiota Regulate Immune Responses Outside the Gut?, In Trends Microbiol, 12(12), 562-568.

Tlaskalová-Hogenová, H., Štěpánková, R., Hudcovic, T. (2004) Commensal Bacteria (Normal Microflora), Mucosal Immunity and Chronic Inflammatory and Autoimmune Diseases, In Immunol Lett, 93(2-3), 97-108.

Hooper, L.V., Littman, D.R., Macpherson, A.J. (2012) Interactions between the Microbiota and the Immune System, In Science, 336(6086), 1268-1273. DOI: 10.1126/science.1223490.

\title{
Наукометрический анализ проекта «Микробиом человека»
}

\author{
С. Пастернак ${ }^{\mathrm{a}}$ Р.Г. Хлебопрос \\ ${ }^{a}$ Исследовательский институт Новой Англии \\ Уотертаун, Миннесота, США \\ ${ }^{\sigma}$ Красноярский научный центр СО РАН \\ Россия, 660036, Красноярск \\ ${ }^{8}$ Сибирский федеральньй университет \\ Россия, 660041, Красноярск, пр. Свободный, 79
}

\begin{abstract}
Появление в 2008 году проекта «Микробиом человека», что сопоставимо по значимости с проектом «Геном человека», является прямым свидетельством осознания важности микросимбионтов для всех аспектов здоровья человека. Качественный наукометрический анализ проведенных в данной области исследований и перспективы их развития является целью данной статьи.
\end{abstract}

Ключевые слова: проект, микробиота человека, соииально значимые исследования.

Научная спеииальность: 22.00.00 - соииологические науки. 